\title{
Redesain Kebun Binatang Surabaya dengan Pendekatan Biophilic
}

\author{
Jafni Zul Fahmi dan Asri Dinapradipta \\ Departemen Arsitektur, Fakultas Teknik Sipil dan Perencanaan, Institut Teknologi Sepuluh Nopember (ITS) \\ Jl. Arief Rahman Hakim, Surabaya 60111 Indonesia \\ e-mail: asdina_p@arch.its.ac.id
}

\begin{abstract}
Abstrak - Surabaya memiliki potensi yang sangat baik pada salah satu tempat rekreasi yang merupakan asset pemerintah Surabaya saat ini. Industri pariwisata semakin berkembang dan semakin diminati. Kebun binatang merupakan objek wisata yang dapat dinikmati oleh masyarakat dari seluruh lapisan usia, selain itu kebun binatang adalah satu-satunya tempat di kota yang memberikan edukasi secara langsung untuk masyarakat mengenai keragaman satwa. Kebun binatang seharusnya bisa menjadi tempat wisata yang menajdi miniatur habitat asli hewan tersebut agar unsur edukasi dan konservasi dapat tercapai dengan maksimal. Kebun Binatang Surabaya memiliki luas 15 hektar dengan koleksi satwa berjumlah 2176 dengan 130 jenis satwa. Beberapa dalam kondisi stres dan sakit yang disebabkan oleh kondisi kebun binatang yang kurang baik. Masalah yang ada diantaranya zonasi, sirkulasi ruang transisi, kelayakan kandang, dan fasilitas pendukung terlihat pada Kebun Binatang ini. Sampai saat ini Kebun Binatang terus mengalami problema di dalam konteks perkembangan kawasan seperti: perkembangan kota, polusi yang semakin meningkat, dan kepadatan serta aktifitas warga kota yang meningkat, untuk itu diperlukan upaya perbaikan atau redesain Kebun Binatang Surabaya dengan pendekatan biophilik yang menjadi acuan dalam pengembangannya, dan diharapkan dapat menyelesaikan masalah yang ada pada Kebun Binatang Surabaya.
\end{abstract}

Kata Kunci-Redesain, Kebun Binatang, Biophilic.

\section{PENDAHULUAN}

$\mathrm{K}$ EBUN binatang Surabaya memilik banyak masalah salah satunya adalah kesejahteraan hewan merupakan masalah yang sangat krusial dan menjadi masalah utama di kebun binatang Surabaya. Faktor yang mempengaruhi kesejahteraan hewan antara lain: ukuran kandang yang kurang memadai, akses visual secara gamblang yang mempengaruhi psikologis hewan jika hewan merasa terganggu, dan faktor external lainnya seperti polusi udara maupun polusi suara. Agar dapat menjalani aktivitas secara normal hewan di dalam kandang sudah sepantasnya mendapatkan ruang setidaknya 8 kali lipat ukuran tubuhnya. untuk itu pemaksimalan lahan sehingga menjadi efisien dengan kebutuhan hewan yang cukup besar harus dapat terselesaikan dengan baik. Kebun binatang Surabaya memilik luas total 15 hektar dengan koleksi satwa berjumlah 2176 terdiri dari 130 jenis satwa. Sejak pertama didirikan KBS sudah sangat berhasil dengan program konservasinya. Namun menurut ISAW jika hewan di KBS dapat berkembang biak dengan baik karena itu adalah kebutuhan biologis, bukan berarti hidup hewan tersebut sejahtera, dengan kata lain keberhasilan konservasi tidak selalu berpengaruh langsung terhadap keberhasilan konservasi di dalam kebun binatang. Redesain diharapkan dapat menyelesaikan berbagai masalah yang ada. Potensi lahan yang seharusnya dapat dimanfaatkan dengan baik tanpa menghilangkan fungsi pendukung kebun binatang, diharapkan dapat meningkatkan kualitas hidup hewan di dalamnya dan peningkatan kenyamanan pengunjung kebun binatang. Dibutuhkan metoda dan pendekatan yang merujuk pada alam, yang berdampak terhadap psikologis perilaku aktifitas di dalam objek bangunan.

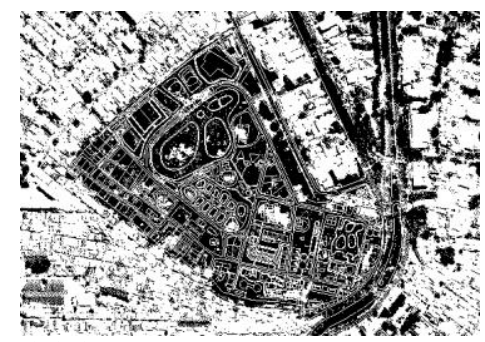

Gambar 1. Lahan Eksisting.
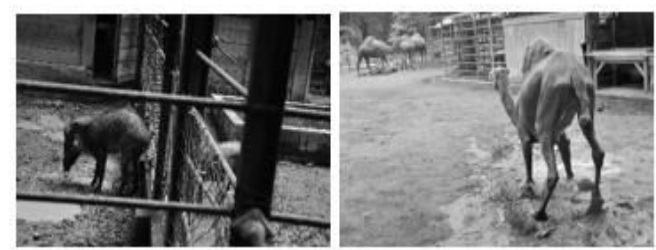

Gambar 2. Kondisi Kandang Eksisting.

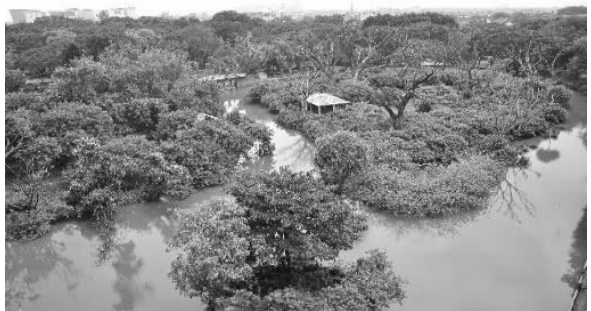

Gambar 3. Kondisi eksisting.
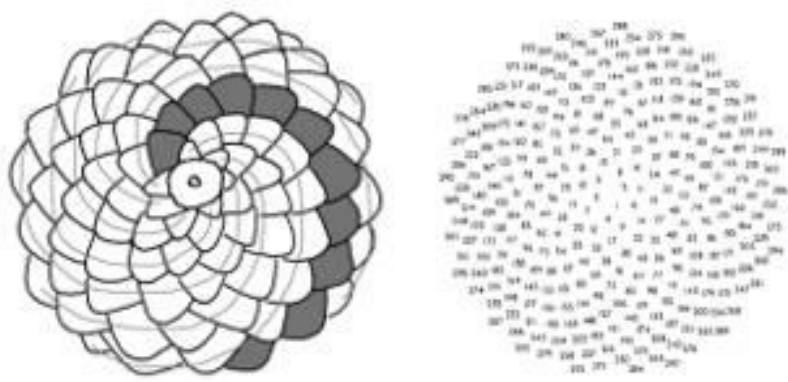

Gambar 4 .Pertumbuhan Dengan Pola Phyllotaxis

Sumber : Dokumentasi Pribadi 


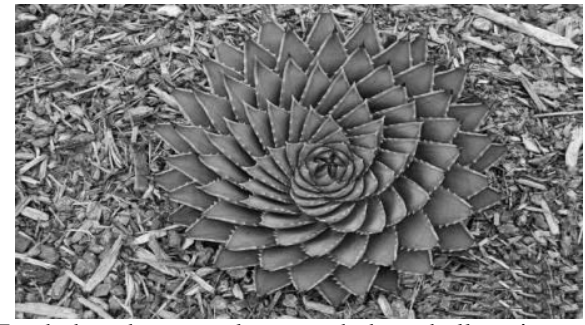

Gambar 5 . Tumbuhan dengan pola pertumbuhan phyllotaxis.

Gambar 6 . pola grid phyllotaxis.



Gambar 7 . Proses Peletakan Grid Pada Lahan.

Sumber : Dokumentasi Pribadi

Gambar 8 . Pengaplikasian Grid Pada Lahan Eksisting

Sumber : Dokumentasi Pribadi

\section{METODA PERANCANGAN}

Metode yang digunakan dalam proses desain ini adalah adalah metode dari John Ziezel "Inquary by Design", menurut Zeizel terdapat tiga langkah utama yaitu, imaging atau menawarkan sesuatu yang baru, kemudian memunculkan kriteria yang memperjelas ide awal yang nantinya akan diterapkan pada rancangan, dan selanjutnya proses testing berupa evaluasi atas desain yang telah dihasilkan berdasarkan pada kriteria-kriteria yang sudah dibuat pada tahap sebelumnya. Untuk terus mengembangkan rancangan, ketiga kegiatan diatas dapat dilakukan berulang hingga dihasilkan desain yang paling bisa menjawab permasalahan di dalam objek desain. Metode ini digunakan karena dengan menggunakan pendekatan biophilic diperlukan banyaknya testing berdasarkan berbagai macam sudut pandang manusia maupun hewan itu sendiri.

Desain dengan pendekatan biophilic adalah cara untuk menghasilkan suatu ruang yang dapat berpartisipasi dalam peningkatan kesejahteraan hidup manusia secara fisik dan mental dengan membina hubungan positif antara manusia dan alam. Pengembangan lahan tepat guna, konservasi dan

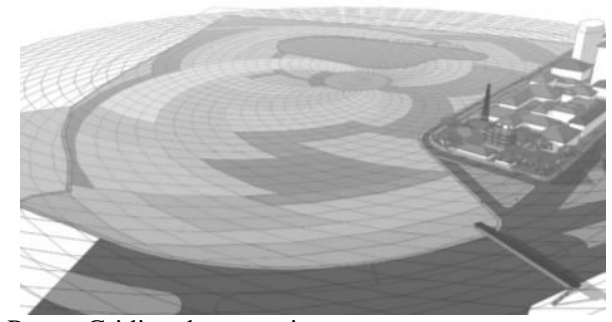

Gambar 9 . Proses Griding dan zonasi

Sumber : Dokumentasi Pribadi



Gambar 10. Transformasi level dan bentuk.

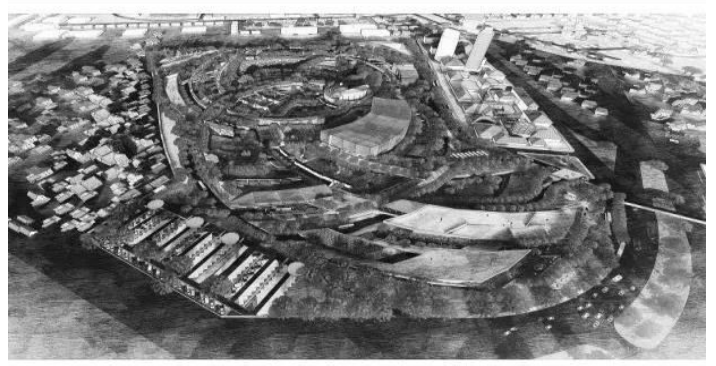

Gambar 11. Perspektif Mata Burung.

Sumber : Dokumentasi Pribadi.

efisiensi energi, bentuk objek bangunan, serta kenyamanan dan kesehatan dalam ruang adalah point-point yang mengandung makna dan tujuan dari desain biophilic itu sendiri. Kategori dalam pendekatan biophilic yang digunakan dalam acuan desain adalah Natural Analogues kategori ini membahas tentang kehadiran alam secara organik dan tidak hidup dengan menyediakan berbagai informasi tentang alam yang terorganisir dengan baik, parameter di dalam kategori ini dapat diaplikasikan ke berbagai aspek di dalam objek bangunan secara keseluruhan. Kategori ini memiliki 3 parameter desain, antara lain:

\section{A. Kompleksitas dan keteraturan}

Unsur alam selalu identik dengan kompleksitas dan acak, baik dalam bentuk dan kondisinya. Namun dibalik keacakannya, keteraturan masih ada di sana pada tingkat yang lebih dalam. Contoh fenomena ini adalah fenomena fraktal simetri yang terdapat pada brokoli, keong dan gunung fraktal. Ketika kita memperbesar objek fraktal, kita melihat pola objek pada tingkat makro diulang pada tingkat mikro, tidak peduli seberapa jauh kita memperbesarnya. 




Gambar 12. Area Drop Off.

Sumber : Dokumentasi Pribadi



Gambar 13. Perspektif Mata Burung.

Sumber : Dokumentasi Pribadi



Gambar 14. Desain KBS Site Plan.

Sumber : Dokumentasi Pribadi

\section{B. Bentuk dan Patra Biomorphic}

Material yang digunakan harus bisa merepresantasikan alam dengan ornament dan tekstur yang tercipta, penggunaan batu alam, kayu dan bahan alam lainnya serta menghindari penggunaan bahan bangunan dengan bahan yang berbahaya, agar mempermudah dama servis bahan bangunan atau bagian bangunan harus mudah diperbaiki dan diganti.

\section{Bentuk dan Patra Biomorphic}

Biomorphic dalah desain yang langsung dipengaruhi oleh hewan, tumbuhan, tubuh manusia dan struktur anatomi dengan bahan yang dipilih untuk menciptakan harmoni estetika. Analogi arsitektur biomorphic diartikan bahwa arsitektur sebagai mahuk hidup yang mengalami metabolisme. Gagasan pertumbuhan tersebut bisa dilakukan secara vertical maupun horizontal. Biomorfik arsitektur berkemampua untuk berkembang dan tumbuh melalui perluasan, penggandaan, pemisahan, regenerasi dan perbanyakan. Pola alam dapat digunakan sebagai grid acuan dalam zonasi. Pola alam yang dapat berkembang adalah pola phyllotaxis. Pola phylluotaxis banyak ditemukan di alam pola ini merupakan symbol pertumbuhan mahluk hidup. Pola ini juga merujuk pada bilangan Fibonacci atau dengan kata lain pola yang tercipta dapat dihitung baik jumlah mauoun luas area masing-masing gridnya. Pola phyllotaxis digunakan sebagai acuan dalam zonasi dan masterplaning pola grid dapat terus berkembang hingga radius yang tak terbatas. Setelah grid diaplikasikan di dalam site penentuan zonasi bangunan di tetapkan berdasarkan kebutuhan barier kandang dari gangguan external seperti suara keributan jalan padat dan polusi udara. Maka area kandang diarahkan melingkar dan berorientasi di tengah, agar area kandang selalu menjauh dari area terluar site, area terluar site digunakan sebagai area bangunan pendukung yang ketinggiannya juga dapat digunakan sebagai barrier suara.

\section{HASIL DAN EKSPLORASI}

\section{A. Eksplorasi Formal}

Bangunan sekitar adalah permukiman warga dengan atap yang konvensional, degan pendekatan biophilic bentuk atap disamarkan dengan greenroof sehingga binatang liar yang berada di kota akan menganggap bahwa objek merupakan tempat yang lebih aman dari ancaman manusia sehingga peran urban wildlife refugee dapat tercapai dengan maksimal. Selain itu desain bangunan yang menyatu dengan site diharapkan dapat memaksimalkan parameter koneksi material dengan alam dan dapat menjadi menara pantau yang digunakan pengunjung untuk melihat situasi kebun binatang secara keseluruhan dari tempat yang tinggi.

Pembagian zoning juga didasarkan pada habitatasli hewan tersebut. Terdapat 3 zona yaitu way kambas, lamandau dan maasai mara. Dengan penggunaan level maka koneksi visal antara hewan terhadap manusia akan terminimalisir dan mengurangi gangguan psikologis terhadap hewan. Zonasi ini adalah pola zonasi yang terbaik dari sekian banyak pilihan.

\section{B. Struktur}

Desain menggunakan rangka kolom dan balok baja. Dengan kolom baja profil berukuran $60 \mathrm{~cm}$ x $60 \mathrm{~cm}$ karena tipe model ini stabil, ditambah lagi beban bangunan adalah greenroof dengan beban pasiv yang sangat berat. Penggunaan material baja diharpkan dapat meminimalisir kesalahan dalam perhitungan dan malfungsi karena Desain bangunan yang sangat kompleks.

\section{Penampungan Air Hujan}

Sebagian besar atap bangunan yang digunakan di dalam site menggunakan greenroof, oleh karea itu pemanfaatan ulang air hujan adalah cara yang paling efisien akan kebutuhan air yang besar di dalam objek kebun binatang. Dalam desain ini sistem utilitas air selain bersumber dari kali sekitar site, air yang digunakan sebagai alternatif juga bersumber dari tandon penampungan air hujan yang berada di setiap green roof dan memanfaatkan gaya gravitasi untuk penyalurannya.

\section{KESIMPULAN}

Redesain Kebun Binatang Surabaya menggunakan pendekatan biophilic dan pola grid phyllotaxis dalam acuan zonasi untuk memudahkan dan mengefisiensi area hewan maupun pengunjung. Selain memudahkan dalam membuat zonasi dengan penggunaan pola ini sikuen kebun binatang ini, interaksi antara manusia dan hewan akan terasa lebih dekat 
namun visualisasi hewan terhadap manusia berkurang karena perbedaan level yang juga menjadi konsentrasi desain dalam objek. Selain itu hewan yang berada di dalam kandang akan merasa lebih tenang dan tidak merasa terkurung dengan efisiensi area yang disebabkan oleh grid phyllotaxis.

Kebun Binatang Surabaya yang baru ini diharapkan dapat kembali menjadi tujuan wisata masyarakat Surabaya maupun kota-kota sekitarnya. Selain itu dengan desain yang baru ini diharapkan akan dapat menambah keefektifan teman kota, dimana burung-burung dan hewan liar kota lainnya dapat singgah maupun berhabitat dengan bebas.

\section{DAFTAR PUSTAKA}

[1] Indonesia Society for Animal Welfare. 2013. Prinsip Kesejahteraan
Satwa di Kebun Binatang. http://isaw.or.id/prinsip-kesejahteraan-satwadi-kebun-binatang/ (diakses 12 Desember 2016).

[2] Fred Lawson, Manuel Baud Bovy. 1977 . Tourism Recreation Development. CBI Publishing Company Inc. Boston, Massac Husets.

[3] Zeisel, J. (1981). Inquiry by design: Tools for environment-behavior research. Monterey, Calif: Brooks/Cole Pub. Co

[4] Yeang, Ken. (2008). Ecodesign: A Manual for Ecological Design. Wiley Academy Zeisel, J. (1981). Inquiry by design: Tools for environmentbehavior research.

[5] Zeisel, J. (1981). Inquiry by design: Tools for environment-behavior research. Monterey, Calif: Brooks/Cole Pub. Co

[6] Neufert, Ernst, Data Arsitek Jilid 1 dan 2, Jakarta, penerbit erlangga, 2002

[7] Adler, David. (1999), Metric Handbook - Planning and Design Data, Architectural Press, UK 